\title{
An Exploratory Study of Recalled Childhood Spiritually Transformative Experiences Among a Specialized Population
}

\author{
Jennifer Elam, Ph.D. \\ Media, $P A$
}

\begin{abstract}
Fifty-three adult members of the American Center for the Integration of Spiritually Transformative Experiences completed an online authorcreated survey about their spiritually transformative experiences (STEs) as children. Included among the survey questions were age at STE; STE contents and aftereffects, both beneficial and challenging, both at home and at school; and recommendations for both experiencers and their parents. Results are reported as descriptive statistics with selected narrative responses. Findings of this exploratory study include that, following their STEs, some participants reportedly felt supported by those around them, but most felt isolated and different from their peers and needed acceptance and affirmation from those closest to them. The article concludes with limitations of the study and recommendations for future research.
\end{abstract}

KEY WORDS: spiritually transformative experiences, childhood, near-death experience, P-12 school

Grown men may learn from very little children, for the hearts of little children are pure, and therefore, the Great Spirit may show to them many things which older people miss.

-Black Elk

\footnotetext{
Jennifer Elam, Ph.D., is a licensed psychologist in both Kentucky and Pennsylvania. She specializes in working with 3-5-year-olds and works currently as a School Psychologist in Early Intervention in Glen Mills, PA. This article is based on Dr. Elam's presentation at the inaugural conference of American Center for the Integration of Spiritually Transformative Experiences (ACISTE) in October of 2012. Correspondence regarding this article should be sent to Dr. Elam at e-mail: jenelam@aol .com.
} 
Since 1969 I have studied, taught, researched, and practiced psychology. For the past 12 years, I have practiced school psychology specializing in work with preschool children and their families. Although addressing spiritually transformative experiences (STEs) falls outside the scope of my job description in the public schools, many times parents have confided that they believe their child's difficulties may be related to an experience the child reported to them and they describe to me-an experience I recognize as an STE. Often, they then get shy and don't want to talk more about it the matter, as it is not part of our formal relationship. I listen compassionately, then do the formal assessment of eligibility for special education, and the STE issues go unaddressed. I have felt both honored that they shared these meaningful experiences with me and frustrated not to have had mechanisms or referral resources to acknowledge and address the important issues surrounding childhood STEs. Because of my interest in these phenomena, I was honored when Yolaine Stout, president of the American Center for the Integration of Spiritually Transformative Experiences (ACISTE) invited me to partner in conducting the research described in this article. Later she invited me to present some initial results of this research at the first annual ACISTE Conference; this article comes from that presentation.

Defining spirituality is like asking a fish to define water (Hart, 2003, p. 6) - a bit difficult to hold onto and know. Hart (2003, p. 7) defined spirit as that unquantifiable force, the mystery that animates all things and of which all things are composed. There is no separating humans from it. ACISTE (2012) has defined an experience as "spiritually transformative when it causes people to perceive themselves and the world profoundly differently: by expanding the individual's identity, augmenting their sensitivity and thereby altering their values, priorities and appreciation of the purpose of life" (para. 1). An STE has the potential for creating greater wellbeing. If the STE is a catalyst for positive growth it is by nature not pathological in itself, even in the minority of cases in which it accompanies a mental disorder. STEs happen to people with strong or weak coping strategies, and a distressing spiritual experience may have the same potential for healthy growth as a non-distressing experience. Though STEs generally have progressive effects on values, attitudes, beliefs, behaviors, and functioning, they also can have regressive or mixed effects (ACISTE, 2012).

A fundamental question about childhood spiritual experiences is how common they are. In a major study, child developmental psychologist 
Tobin Hart and a colleague asked 450 young adults about specific spiritual experiences, including "moments of wonder and awe, unitive experiences, and receiving spiritual guidance from a nonphysical source" (Hart, 2003, p. 6). They found that, depending on the specific type of experience, $10-80 \%$ reported having experienced it, and $60-90 \%$ reported having first experienced it during childhood (pp. 6-7).

Their findings corresponded to my own research experience. When I began researching mystical experiences and word got around that I was a safe person to talk to, I had more people to talk to than I could possibly arrange. Many of the people I did talk with described experiences from their childhoods, and most told me they had never or almost never talked about their experiences because they did not feel safe to do so. From research like Hart's, from Sutherland's (2009) summary of research on the childhood STE of near-death experiences (NDEs), and from my own experience, I have concluded that people representing a large segment of the child population have had and are having non-ordinary experiences that they are not sharing (Elam, 1999, 2002). In Hart's words, their experiences do, indeed, represent a largely secret spiritual world (Hart, 2003).

\section{Methods}

The present exploratory research involved asking adults about their childhood STEs. Members of ACISTE, along with other individuals in related social networks, were invited by e-mail to complete a 25-question survey inquiring as to the details of their childhood STEs. The online research tool Survey Monkey was used to gather survey responses. General qualitative analysis was performed on survey responses, as was descriptive quantitative analysis such as counting the frequency of occurrence for particular phenomena. In order to protect participant confidentiality, the names that appear below are pseudonyms.

The following data are based on a total of 53 completed response sets. Comparison of the response sets revealed unique answers that indicated each set was submitted by a different participant. However, as we did not block multiple submissions from the same IP address, submission of two unique response sets from the same participant cannot be ruled out. The assumption for the following material is that the response sets represented 53 different participants.

Participants' ages in years ranged from the teens decade to the $80 \mathrm{~s}$ decade, with most respondents in their 50s and 60s. We did not ask re- 
spondents to report their gender or ethnicity. However, from narrative responses, we sometimes could discern a participant's gender; when we could, we used the appropriate pronoun in reporting qualitative findings, and when we couldn't we used "s/he."

\section{Results}

The following material reflects what I consider the most salient from among all the results of the survey. Results appear in an order that makes conceptual sense rather than the exact order of the survey questions.

\section{First STE}

Age. We asked participants their age at their first STE-from prebirth up to 15 years-and determined the percentage of participants at each age. The most likely ages in order of highest percentages were $4(n=9 ; 17 \%), 5(7 ; 13.2 \%), 7(6 ; 11.3 \%)$, and $3(5 ; 9.4 \%)$ years. Two participants (3.8\%) reported pre-birth memories, and in the age range 12-15 years, only one participant (1.9\%) reported an STE-at age 15.

Memory. When participants were asked if they remembered their first experience immediately after it happened, $42(79.2 \%)$ said yes, and $11(20.8 \%)$ said no, that they recalled it only later. If they recalled the experience later, we asked how much later and asked them to describe any circumstances that might have prompted them to remember the STE. As detailed below, the circumstances around the remembrance were quite varied. Some involved others telling them of the experience, some had a re-occurrence such as another STE, and others had a non-spiritually-transformative experience that triggered the memory of the childhood STE.

One participant said s/he heard voices and did not pay attention to them at age five but discovered the importance of them later. One did not feel s/he had the intellectual development to understand the experience but later recalled it in an insight as an adult with a greater capacity for understanding. One reported that when s/he sees or hears something out of the ordinary it's recorded like a biological video in the mind. One had a recurring dream for years throughout childhood and put the pieces together later, stating that "The 'Dream' is my spirit returning to my fetus." One said the experiences tended to happen at bedtime; in later years, "whenever I lay down, I would remember the 
experience and wonder if I could make it happen again." One said that she forgot about the experiences as an adult until she had a life review in an NDE at age 32 and then saw herself as a child "hanging out in the tunnel." Similarly, another said she forgot until she later connected with the experience in an awakening. Another participant said s/he realized after 50 that, "I could still feel the tension from the original experience within my chest. It was like a ball of boiling energy. As I began for the first time to focus in on this energy, it began to give up all the memories related." Another participant used hypnotic regression to recover memories from a "missing week." Similarly, another participant remembered the experiences while doing a psychotherapy exercise for the treatment of obsessive-compulsive disorder.

Duration. Participants were asked to estimate how long the first experience lasted-from an observer's point of view. Responses ranged from impossible to estimate $(n=14 ; 26.4 \%)$ to less than a minute $(10$; $18.9 \%), 1$ to 60 minutes (18; 34.0\%), more than an hour (2;3.8\%), more than a day (2; 3.8\%), more than a month $(3 ; 5.7 \%)$, and it never stopped (4; 7.5\%). Thus, duration showed a pattern of decreasing length, with approximately one-quarter of participants indicating they could not estimate, one-half indicating less than an hour, and the remaining one-quarter indicating more than an hour including a few who indicated the experience had been ongoing to the present.

Circumstances. When participants were asked whether their first STE was triggered by physical or emotional trauma or involve abuse, illness, injury, drowning, accident or other adverse circumstances, 29 $(54.7 \%)$ said yes, 18 (34\%) said no, and $6(11.3 \%)$ said they were not sure. If yes or not sure, they were asked to describe what happened. After examining the "not sure" narratives, we concluded that at least $35(66.0 \%)$ of our participants' STEs were either directly or indirectly related to trauma. Analysis of the themes of their narratives revealed that these participants have been doubly challenged, both by the original trauma, that was often ongoing, and by the predominant culture, that often not only did not support these childhood trauma victims but also labeled their spiritual experiences as mental illness.

Some of the specific circumstances were described as follows: "was found dead in my crib, smothered then revived violently," "much emotional and some physical trauma with an aggressive, alcoholic mother," "was run over by a car," "had stopped breathing while asleep and was aware of my heart stopping and my body shutting down," "was stung 
by a nest of bees, fell unconscious, and woke up in the emergency room," "was raped and had a near death experience," "my father beat my mother during my gestation," "was attacked by a dog and as his mouth was about to close around my throat I had my life review; from this, 'other' experiences began to occur," "had measles twice around 8 months old," "was a nervous child," "I had been being sexually, physically and emotionally abused by family members for most of my life," "suffocated with a pillow in the cradle at age three months, but recovered," "suffered fetal trauma and then birth trauma," "was drowned by my own mother but brought back to life by her too; luckily she was a nurse," "tonsillectomy," and "it happened during child abuse event."

Alignment with family's religion/spirituality. Participants were asked the religious or spiritual orientation of their closest parent, foster parent, or other adult in charge of their upbringing at the time of their first experience and to choose the most accurate answer from a series of choices. From most to least of those who indicated a choice, 17 (32.0\%) indicated Catholic, 13 (24.5\%) Protestant, 7 (13.2\%) Baptist, 2 (3.8\%) Jewish, 1 (1.9\%) Native American, 1 (1.9\%) Spiritual, non-denominational, and 1 (1.9\%) Atheist. One participant (1.9\%) indicated s/he didn't know, and of the 10 (18.9\%) who indicated "Other," participants noted Mormonism, Scientology, secular Judaism, Quaker grandmother, and Jehovah's Witnesses; one participant thought the caretaker believed in God; and one said the household was mixed, as the mother was Protestant and the father was Catholic; and one noted that her mother was bitter about religion.

Participants were then asked if their experience was in alignment with their family's religious beliefs. Only 4 participants $(7.5 \%)$ indicated alignment; 2 (3.8\%) indicated No, but my parents were supportive anyway; 7 (13.2\%) indicated No, and it created problems, 15 (28.3\%) indicated they didn't know, and 25 (47.2\%) indicated Other.

Confidantes and their reactions. When participants were asked if they shared their first spiritual experience with someone soon after it happened, $21(39.6 \%)$ said yes, and $32(60.4 \%)$ said no. Eventually, all participants did disclose their first experience to someone else. From most to least reported, 12 (22.6\%) indicated a parent, 10 (18.9\%) indicated a friend, 2 (3.8\%) indicated an extended family member, 2 (3.8\%) indicated a psychotherapist, $1(1.8 \%)$ indicated a teacher, none indicated a sibling, and 26 (45.3\% indicated Other. Two participants (3.8\%) said they had never shared with anyone until now. Among those who 
responded Other, written responses indicated that as adults they have shared their experiences with many people: spouse, adult children, siblings, grandmother, mother, teacher, friends, family, therapist, Taoist priest, church congregation, school, spiritual director, counselor, and spiritual mentor. Some have shared with so many people, they don't remember who all they were.

The nature of their confidantes' responses, from most to least frequently reported, were $13(24.5 \%)$ who thought the experience was the participant's imagination, $8(15.1 \%)$ who were supportive, 7 (13.2\%) who didn't know what the confidante thought, 6 (11.3\%) whose confidantes wanted to hear everything about the experience, 5 (9.4\%) who ignored it, 4 (7.5\%) who were angry, 4 (7.5\%) who were worried, 2 (3.8\%) who were encouraging, $2(3.8 \%)$ who took the participant to a minister or other spiritual advisor, 1 (1.9\%) who were excited, $1(1.9 \%)$ whose mother and father responded oppositely, and none who took the participant to a mental health professional either in or out of school. Thus, 17 (32.1\%), or about one-third of participants, reported responses that could be considered beneficial-supportive, encouraging, excited, wanted to hear everything; 9 (17\%) reported responses with a neutral or undeterminable valence-didn't know what the confidante thought, took participant to religious/spiritual advisor; and the remaining 27 (50.9\%), or about half of participants, reported unhelpful or detrimental responses.

Twenty-one participants (39.6\%) made comments related to responses they received from disclosing their first childhood STEs as teens or adults. The responses seemed to range from somewhat supportive to mixed to somewhat dismissive to very dismissive. Somewhat supportive comments included "They couldn't understand it but accepted it. The Taoist priest had a better understanding," "Supportive but not that interested," "Before my mother passed, I read her some NDEs off the web; she then remembered smelling and hearing her mother during a time she was in a coma," "Mother was resistant at first, has become more interested and open," and "In my country, spirits are a common sight and it's part of life, common knowledge in other words." Mixed responses included "Some like it. I have been told it was creepy or weird. My mother found it fascinating. Never told my dad," "They thought I was either nuts or that I was finally a good Catholic, but wanted me to think and talk about it less," and "What little they showed interest, they mostly showed shock and fear that it happened at all, most likely because it involved a sibling and was violent and caused me to die and then return." 
Several participants never shared their experience or said they had to wait for just the right time to share it. They did not perceive it to be safe, others told them not to tell, or they tried to tell it and got an angry or other negative reaction as an initial response and did not attempt it again, but most did talk about it years later. Some of the negative responses included "My dad thought I was possessed, got me blessed by a priest, and his mother would douse me with Lourdes water (Holy Water) every time I entered her home," "At age 4 I shared an after effect (seeing a fairy) with my parents; when they rejected both the experience and fairies, I determined never to share ESP events with them again and never did, although my entire life has been filled with them," "I told my mother a few years ago; she was dismissive and uninterested," "I told my teacher and she told my mother who seemed embarrassed," and "I tried to talk to my mother once about the ghosts and witches in my bedroom at night, but she thought it was imaginary, so I never shared anything else."

Some participants referred specifically to labels and diagnoses they had received in response to disclosing their STEs. One participant said s/he was described as "creative and dark." Another was called a "deep weirdo." "Over-active imagination" was a common label.

One participant noted that the family was following scientology so, for religious reasons, they did not seek professional help that might or might not have led to diagnosis. Diagnoses given to other participants and thought perhaps related to their STE included: premature baby $(n=2 ; 3.8 \%)$, ADHD (1; 1.9\%), sleep disorder (3; 5.7\%), and PTSD (1; $1.9 \%)$. Some diagnoses were made but were thought not related to the STE and included: premature baby $(1 ; 1.9 \%)$, ADHD/ADD (2; 3.8\%), personality disorder $(3 ; 5.7 \%)$, dissociation $(2 ; 3.8 \%)$, and post-traumatic stress disorder (PTSD; $2 ; 3.8 \%$ ).

Some participants spontaneously commented on the role of confidante responses in participants' integration process. For most participants, the STEs had both a blissful, peaceful, beautiful component as well as a painful component, and several described becoming fearful when the people around them could not cope with the STE or its aftereffects. Thus, reactions of others could make the experience easier or more difficult to integrate. Acceptance from others and the ability to make meaning from the experience seemed to be associated with more ease in integration. 


\section{Subsequent to First STE}

STEs after the first. Participants were asked if they had spiritual experiences after the first and were given specific choices for answers. From most to least frequent, 32 (60.4\%) participants reported multiple STEs throughout their lives, 11 (20.8\%) indicated a few STEs as both a child and an adult, 7 (13.2\%) indicated more than one, and $3(5.7 \%)$ indicated recalling only the one childhood STE. Thus, the great majority of participants reported many STEs throughout their lives.

Six participants commented on their later STEs. One said that none of the later ones were as profound as the first. One said that as an adult, s/he continued to have many different kinds of spiritual and mystical experiences. One said she did not remember the experiences until, during her NDE life review, she saw herself in the tunnel as a child. One said she has had some strange events in her life but would not call them STEs; for example, she heard someone talk to her as if they were in the room with her, but no one was there. One described a feeling of "other worldliness" of communication with the divine while in the mountains by a creek. Another described being saved from death or severe physical trauma in inexplicable ways and experiencing an omniscient Presence, an energy full of love and benevolence much larger than herself that enveloped her body multiple times throughout her life.

\section{Contents of most profound or transformative childhood STE.} Participants were asked to describe what happened in their most profound or most transformative childhood spiritual experience thus, this particular topic included what might or might not have been respondents' first STEs. Responses were varied. The largest subgroup reported NDEs. Several of these involved drowning, and these participants all reported a very similar pattern. They described going under the water. Very soon, they entered a peaceful, beautiful place and could look down on the(ir) body. Often a voice told them it was not yet their time to stay, and they were then catapulted back into their bodies-a process that most participants described as painful, except for one for whom it was a calm re-entry. Angels were often involved in these drowning NDEs.

The second largest subgroup of STEs also involved various kinds of out-of-body experiences, though not apparently during close brushes with death. The third largest subgroup of experiencers heard voices and/or had visions, such as lights and auras. Some participants could 
see or hear spirits that others could not perceive. Communicating with spirits, God, or angels was often involved. Some participants reported "knowings" during their experiences-knowing things they could not have known by rational means.

For several participants, traumatic content was co-mingled with STE contents. For some of those participants, the traumatic contents involved abuse by another person.

School experiences and performance. Participants were asked to indicate all items that applied from a list of various school experiences that they attributed directly or indirectly to their STEs. Of the $34(64.2 \%)$ of participants who indicated one or more listed items, 15 made comments. Responses appear in Table 1, first participants who did not indicate any items or indicated no STE-related school issues and then items from most to least indicated.

Table 1

School Experiences Participants Directly or Indirectly

Attributed to Their STEs

\begin{tabular}{lrc}
\hline Type of Experience & $n$ & $\%$ \\
\hline None of the below items indicated & 19 & $35.8 \%$ \\
I had no issues at all at school because of my STEs. & 7 & $20.6 \%$ \\
I kept to myself because I felt different. & 21 & $39.6 \%$ \\
I found an outlet through play, art, music or dance. & 12 & $22.6 \%$ \\
I was bullied or teased by other children. & 9 & $17.0 \%$ \\
Other children thought I was weird and avoided me. & 7 & $13.2 \%$ \\
My STE(s) distracted me from my learning. & 7 & $13.2 \%$ \\
I made friends with kids who also had spiritual experiences. & 4 & $7.5 \%$ \\
I was placed in a class for the gifted. & 4 & $7.5 \%$ \\
I was sent to the school psychologist. & 3 & $5.7 \%$ \\
I was placed in special education. & 2 & $3.8 \%$ \\
I was sent to private or religious school. & 2 & $3.8 \%$ \\
My teacher embarrassed me about my experience(s) in front & 2 & $3.8 \%$ \\
$\quad$ of the class. & & \\
I acted out or was angry. & 2 & $3.8 \%$ \\
My parents kept me out of school. I was home schooled. & 0 & $0.0 \%$ \\
My friends and teachers were very receptive and accepting. & 0 & $0.0 \%$ \\
\hline
\end{tabular}

Note. $N=53$. Percentage exceeds $100 \%$ because some of the 34 respondents who indicated at least one item indicated more than one item. 
Participant comments indicated a full range from those who excelled in school to those with significant difficulties. Comments indicating no school difficulties included, "I excelled in all areas, top of my class." Regarding peer relations, comments included, "I was compassionate toward sad, poor or disadvantaged children." One participant made friends because she was always drawn to others who had had spiritual experiences. Another noted that she did not know she was different until years later. Yet another said, "While I felt older than my peers, I adapted and got along with them."

Seven of the 15 participants who commented indicated that they had difficulties in school ranging from mild to more significant school difficulties. Comments included: "I longed to feel connections and wanted to feel like I belonged somewhere," "I felt different and did not like a lot of what they were trying to teach me," "I was sent to the guidance counselor. I had a genius IQ but was not doing well in school. I told her that I sometimes talk with plants and animals but she thought I was just 'imaginative," "I became solitary and trusted no one other than the enlightened few," "I was (am) dyslexic. I struggled in school yet was considered very mature for my age," "I couldn't learn like other children and found that any distraction prevented my ability to learn. Once I was placed in an isolated setting, I excelled in everything and got straight A's," and "immediately after the NDE, I knew how to read though no one had taught me. I was bored and disaffected throughout K-12 years, and made terrible grades. Though I had a high IQ, I was always in trouble. No problems in college/grad school (it wasn't so boring),"

\section{Observations in Retrospect}

Effect of childhood STEs on adult lives. Fifty-two (98.1\%) participants responded and commented on how the STEs of childhood affected their adult lives; one could not because of being only 15 years old. Because participants could indicate more than one answer, the following percentages exceed $100 \%$.

Three (5.7\%) participants commented in essence that the change had been pervasive. Among the seemingly constructive effects: Five (9.4\%) indicated that the experiences had enhanced their spiritual lives in such ways as enhancing her/his belief in the supernatural, having opened her more fully to her spiritual life, transforming her life spiritually, moving from an agnostic to a more spiritual outlook on existence, or relating to the experiences when she studies spiri- 
tualism. Three (5.7\%) participants talked about how the experiences provided a foundation to their later vocations as a pastor, an NDE researcher, and a writer of books on angels. Among the seemingly challenging effects: Feeling different was a theme that arose for one $(1.9 \%)$ who said she still feels as if she does not belong and one (1.9\%) who said she feels like she was treading water all her life but finally understands why she has been the way that she was. Fear was a part of the feeling for three (5.7\%) people, one who said she felt different, not loved, alone and was afraid to be alone; one who said people became afraid of her so she had to be very careful; and one who said her family became afraid of her, which was very hurtful.

There were those who found the experiences to enhance their lives in very desirable ways, for some it was very difficult and for some the experiences both enhanced their lives and made life more difficult. Those for whom the experience enhanced their lives said "it opened my eyes and all the senses to observe things in greater detail and beyond the "normal," "made life amazing and enlightening," "steered me onto a spiritual path which has brought immense gifts of grace and love to me, am grateful, and wish it could be transmitted or induced," "understand why it happened and am at peace," and "helps me understand the afterlife and my life is whole ... my heart is pure with no anger or grief." Other said, "... empowers me ... it provides assurance that I am not fabricating stories," "I feel deeply enriched and blessed by grace and hope," ". . . more receptive to other people's spirituality," "made me who I am," "made me a very strong and peaceful person. I help many people cross over to death. I never search it out but there have been many opportunities that have dropped into my awareness." One said, "more understanding of people, not afraid of death and try to let people know that death is not the end." Three participants stated that the effect was positive or it helped.

Those who found their experiences made life harder said, "I have the spirit of a warrior, martyr, it hasn't been easy," "I'm constantly feeling inadequate and depressed with a mixture of anger," ". . . professionally, it is much harder because my reputation is on the line and I wish I had had the support that I see available now ...," and "... more problematic. Less idealistic and more serious about eternal security/ after death. ..." Those for whom the experiences have had mixed effects said, ". . . double-edged sword-gifts and challenges,” “. . . still afraid of the dark and can't sleep alone. However, it has made me very curious about the spiritual world ...," and "... have come into 
more acceptance of my unusual life and I've found 'kindred spirits' who respect my path and share aspects of it."

Life challenges created by STEs. Participants were asked about what challenges were created in their lives by their STEs; once again, due to multiple responses by some participants, the following percentage exceeds $100 \%$. Nine participants (17.0\%) said none, and one attributed an absence of challenges to not having disclosed the experience to anyone. Five participants (9.4\%) indicated not being able to talk about their experiences or having no one to talk to. One person $(1.9 \%)$ indicated not having someone to help her or him.

Most frequent was the 17 participants (32.1\%) who reported feeling different, with some noting their efforts to be "normal" while believing they were not. Values were different and fitting in was difficult. One person described feeling like she was "born on the wrong planet." Associated with the feeling of being different were other feelings of isolation or loneliness $(n=4 ; 7.5 \%)$, mistrust $(2 ; 3.8 \%)$, and one $(1.9 \%)$ each: fear or anxiety, anger and depression without an identifiable source, difficulty sleeping, and lowered self-esteem. Two participants (3.8\%) reported an increased sensitivity to seeing through falsehoods, facades, or deceit. "Knowing too much" $(1 ; 1.9 \%)$ was an issue. Five people $(9.4 \%)$ reported issues with peers: feeling older than peers, being drawn to adults, and being bored with what peers are typically interested in. Two people (3.8\%) reported needing to be very careful so that they did not scare others.

Other challenges included disclosure met with discounting or disbelief ( $n=3 ; 5.7 \%)$ and school difficulties $(3 ; 5.7 \%)$ to the point of "torture" $(1 ; 1.9 \%)$. Two participants $(3.8 \%)$ reported that they did not want to live their given human lives, with one stating that she just wanted to be with the angels. Living with two opposite realities, one accepted by the culture they lived in and one marginalized by the culture was very challenging.

What was needed in childhood. When adults were asked specifically what they needed as children, the responses presented a clear picture. Most said validation/affirmation and knowledge to help them understand the experience(s). An open-minded mentor, teacher, counselor, someone safe, a loving adult to give knowledge $(n=22 ; 41.5 \%)$ as well as validation, affirmation, telling them it was ok or normal, and that there were other children like them (12;22.6\%). Respondents 
would have liked to be listened to without judgment or fear $(9 ; 17.0 \%)$, with adults interested enough to ask questions $(1 ; 1.9 \%)$ and help with integration $(1 ; 1.9 \%)$. One participant (not the same one) indicated each of the following: Being protected from their own fear was important, as was privacy, nature, art, and changing to a different school. Four respondents $(7.5 \%)$ felt their needs were well taken care of as children, and four did not know what they would have needed.

Advice to children and parents. Participants were asked what advice they would give to children having STEs and to their parents; again, multiple responses caused total percentage to exceed 100\%. Responses to children included to trust themselves and their own experience as real, normal, and acceptable and to find trustworthy others and confide in them $(n=21 ; 39.6 \%)$. Other advice included to release fear $(4 ; 7.5 \%)$; to find a mentor $(3 ; 5.7 \%)$. Each of the following recommendations was endorsed by one $(1.9 \%)$ participant (not the same one): to know that they are special and gifted, to not allow their experiences to be discounted, and to seek out others like themselves; not to try to convince others; to seek knowledge about experiences like theirs; to live the spiritual life; to ask for help from their higher power; to spend time in nature; and to have a pet.

Participants advised parents to listen $(n=15 ; 28.3 \%)$ nonjudgmentally $(3 ; 5.7 \%)$, love unconditionally $(6 ; 11.3 \%)$, and physically hold (2; 3.8\%) and emotionally support (8; 15.1\%) their STEr children. They urged parents to allow children to talk about the experience $(3 ; 5.7 \%)$ when they are ready $(1 ; 1.9 \%)$ and make no big deal about it $(3 ; 5.7 \%)$. They also recommended that parents take their children's experiences and feelings seriously $(3 ; 5.7 \%)$, not dismissing them as mere imagination and that they believe in the reality, or believe in the possible reality, of their children's STEs (8; 15.1\%). They advised parents to get involved, be interested, and ask questions that help children to further clarify/define (5; 9.4\%) and integrate $(3 ; 5.7 \%)$ their experiences. They admonished parents to be honest with their children about what they do and don't know about STEs and to educate themselves about them (14; 26.4\%), with the specific suggestion of Tobin Hart's (2003) book The Secret Spiritual World of Children. One participant (1.9\%) urged parents to use discernment to find children that their children felt were like them to be with. Participants suggested that parents write down the experiences or make notes to come back to later $(2 ; 3.8 \%)$, consider using the arts to help with expression $(1 ; 1.9 \%)$, and consider taking their child to play therapy $(1 ; 1.9 \%)$, a counseling intervention 
appropriate for children ages $3-9$ years old. They said parents should help children discover and cultivate what they love in life $(1 ; 1.9 \%)$ and should normalize $(3 ; 5.7 \%)$, avoid labels, and not treat children as if they are crazy ( 3 ; 5.7\%). They advised parents to consider their children's experiences a blessing rather than a worry $(2 ; 3.8 \%)$, to know it is a gift that will also be a blessing to others $(3 ; 5.7 \%)$, and, if they find themselves unable to listen deeply to their children, to find someone who can $(1 ; 1.9 \%)$.

Participants expressed mixed opinions on some parenting issues. Some found psychotherapists helpful and some said to avoid therapists or professionals; the key seemed to be whether or not the therapists had had STEs themselves and were knowledgeable about them. Some advised participation in church, but most advised to avoid church if the church philosophy was judgmental. One person advised avoiding public schools and teaching the child at home; others indicated that public or private school experiences could be good for childhood STErs but that parents should monitor their school experiences to identify and address any problems that might arise.

\section{Limitations of the Study, Future Research, and Conclusion}

The generalizability of the results reported herein is restricted by numerous limitations. These included that the sample size was small, that the population from which the sample came was very specialized, that reports of childhood STEs and reactions to them were mostly distantly retrospective, and that the instrument did not have established psychometrics such as validity and reliability-a limitation that became clearer when respondents indicated that their answers to the questions did not appear among the response choices. Thus, the results of this study can be considered only preliminary and exploratory.

However, the results herein establish that at least some childhood STErs recall a variety of experiences and responses to their STEs. From the participants sampled in this study, the takeaway messages for both children and those who interact with them are numerous. As most STEs reportedly occurred between ages 3-7 years, and fourfifths of STErs recalled the experiences immediately, it should not be surprising that children at such young ages report STEs-especially, but not only, if they have survived physical or emotional trauma. Most children will report experiences that lasted less than an hour, though 
a minority may report longer experiences-even ongoing to the present. Drowning NDEs may be a most frequent circumstance and type of STE, though children may also report other out-of-body experiences and/or voices and visions of entities such as spirits, angels, and God. If a child reports one STE, they almost certainly will report subsequent ones.

Among this sample, the most likely people to whom children disclosed their STEs were parents and friends, and participants affirmed that confidante's responses were important-often crucial-in STErs' integration process. Although one-third reported beneficial responses, one-half unfortunately reported detrimental ones. As one-tenth of this sample indicated that a conflict between the contents of the STE and one's caretaker's religious/spiritual beliefs created particular difficulty, caretakers who wish to be most helpful to their children need to be prepared to open their minds beyond cherished beliefs and valuesfor many an admittedly challenging process. And though some participants in this sample reportedly excelled at school, two-thirds reported some difficulty in school-occasionally agonizing.

Though these childhood STErs reported both positive and negative effects of the STE throughout their lives, a persistent theme across the lifespan was a sense of psychospiritual isolation. Not surprisingly, then, these participants reported that what they had needed most as children was affirmation/validation of their experiences and themselves as well as information about STEs and how to manage them. Their most endorsed advice to children was to trust themselves and find trustworthy others to validate/affirm and inform-and to parents was to be that trustworthy source of validation/affirmation and information. In utilizing community resources to help STEr children, these respondents recommended religious/spiritual consultants who also will nonjudgmentally validate/affirm and inform, and mental health professionals with at least professional expertise about, if not personal experience with, STEs. In summary, participants encouraged children, and encouraged parents to help children, to acknowledge rather than avoid the STEs and to take any of a number of possible actions to integrate the experiences, cultivating their enhancing aspects and managing or reducing the challenging aspects.

It remains for future research to determine how representative the results of this survey are among children at large in both U.S. and other cultures as well as how effective participants' recommendations prove to be in easing and facilitating the STE integration process for children. For example, whether the absence in this sample of reported 
STEs at ages 12-14 years represents a sampling error or an actual trend remains to be determined; certainly, no such trend has been identified with regard to NDEs (Sutherland, 2009). Pending further research, it is noteworthy that participants' recommendations to STEr children and their parents correspond to professionals' advice about responding to transpersonal experiences among children and in general (Bell, Holden, \& Bedwell, 2010; Foster, Holden, \& James, 2009: Kason, 2009; Sutherland, 2009); as such, in the absence of effectiveness research, these recommendations represent the best available guidance for childhood experiencers and their parents. The results of the study described herein hopefully will inspire future researchers to further examine the nature of childhood STEs and aftereffects and the most helpful ways for experiencers and their parents and other associates to respond to them.

Some participants reported quite distressing childhood abuse experiences arising from their STEs, primarily in their families but sometimes in their schools. As a school psychologist, this finding is quite concerning to me. I am hopeful that parents and families, school personnel, and health professionals will use the information in this article to create physically and psychologically safe spaces for people of all ages to share their STEs and move toward integration in a timely manner so that they do not have to spend decades struggling with experiences that have the potential for enhancing life with joy and spiritual connection.

\section{References}

American Center for the Integration of Spiritually Transformative Experiences. (2012). What is a spiritually transformative experience? Retrieved from http:// www.aciste.org/index.php/about-stes/what-is-an-ste

Bell, K. E., Holden, J. M., \& Bedwell, J. (2010). How school counselors can assist student near-death experiencers. Professional School Counseling, 14(2), $165-173$.

Elam, J. (1999). Dancing with god through the storm: Mysticism and mental illness: Pendle Hill pamphlet \#344. Wallingford, PA: Pendle Hill.

Elam, J. (2002). Dancing with god through the storm: Mysticism and mental illness. Media, PA: Way Opens Press.

Foster, R. D., James, D., \& Holden, J. M. (2009). Practical applications of research on near-death experiences. In J. M. Holden, B. Greyson, \& D. James (Eds.), The handbook of near-death experiences: Thirty years of investigation (pp. 235-258). Santa Barbara, CA: Praeger/ABC-CLIO.

Hart, T. (2003). The secret spiritual world of children. Makawao, HI: Inner Ocean Press. 
Kason, Y. (2009). Farther shores: Exploring how near-death, kundalini and mystical experiences can transform ordinary lives. New York, NY: iUniverse.

Sutherland, C. (2009). "Trailing clouds of glory:" The near-death experiences of Western children and teens. In J. M Holden, B. Greyson, \& D. James (Eds.), The handbook of near-death experiences: Thirty years of investigation (pp. 87108). Santa Barbara, CA: Praeger/ABC-CLIO. 